\title{
Microstructure and Corrosion Behavior of Ni-Alloy/CrN Nanolayered Coatings
}

\author{
Hao-Hsiang Huang,, ${ }^{1}$ Fan-Bean Wu, ${ }^{1}$ Jyh-Wei Lee, ${ }^{2}$ and Li-Chun Chang ${ }^{2}$ \\ ${ }^{1}$ Department of Materials Science and Engineering, National United University, Miaoli 36003, Taiwan \\ ${ }^{2}$ Department of Materials Science and Engineering, Ming Chi University of Technology, Taipei 24301, Taiwan
}

Correspondence should be addressed to Fan-Bean Wu, fbwu@nuu.edu.tw

Received 23 April 2010; Accepted 19 August 2010

Academic Editor: Bo Zou

Copyright (C) 2011 Hao-Hsiang Huang et al. This is an open access article distributed under the Creative Commons Attribution License, which permits unrestricted use, distribution, and reproduction in any medium, provided the original work is properly cited.

\begin{abstract}
The Ni-alloy/CrN nanolayered coatings, Ni-Al/CrN and Ni-P/CrN, were deposited on (100) silicon wafer and AISI 420 stainless steel substrates by dual-gun sputtering technique. The influences of the layer microstructure on corrosion behavior of the nanolayered thin films were investigated. The bilayer thickness was controlled approximately $10 \mathrm{~nm}$ with a total coating thickness of $1 \mu \mathrm{m}$. The single-layer Ni-alloy and $\mathrm{CrN}$ coatings deposited at $350^{\circ} \mathrm{C}$ were also evaluated for comparison. Through phase identification, phases of Ni-P and Ni-Al compounds were observed in the single Ni-alloy layers. On the other hand, the nanolayered $\mathrm{Ni}-\mathrm{P} / \mathrm{CrN}$ and $\mathrm{Ni}-\mathrm{Al} / \mathrm{CrN}$ coatings showed an amorphous/nanocrystalline microstructure. The precipitation of $\mathrm{Ni}-\mathrm{Al}$ and $\mathrm{Ni}-\mathrm{P}$ intermetallic compounds was suppressed by the nanolayered configuration of Ni-alloy/CrN coatings. Through Tafel analysis, the $E_{\text {corr }}$ and $I_{\text {corr }}$ values ranged from -0.64 to $-0.33 \mathrm{~V}$ and $1.42 \times 10^{-5}$ to $1.14 \times 10^{-6} \mathrm{~A} / \mathrm{cm}^{2}$, respectively, were deduced for various coating assemblies. The corrosion mechanisms and related behaviors of the coatings were compared. The coatings with a nanolayered $\mathrm{Ni}$-alloy/CrN configuration exhibited a superior corrosion resistance to single-layer alloy or nitride coatings.
\end{abstract}

\section{Introduction}

Nanolayered thin film was recognized as a coating with alternating layers of two different materials with dissimilar physical, chemical, and related characteristics. With proper control of layer composition and microstructure, multilayered coatings could yield superior mechanical properties than monolayer ones [1-5]. Chromium nitride thin films have been investigated and demonstrated to exhibit good mechanical performance, thermal properties, and antioxidation behavior [6,7]. Also, Ni-based alloy coatings were frequently adopted as protective alloy coatings due to their various merits, including corrosion resistance, toughness, and wear resistance $[8-10]$. The combination of these two materials systems to form a dual layer composite coating was a possible way to further the coating properties [1113]. Several materials systems with nanolayer configuration, such as $\mathrm{CrN} / \mathrm{AlN}$, TiN/CrN, $\mathrm{Ag} / \mathrm{Pd}$, and $\mathrm{Au} / \mathrm{Ag}$, had been developed [1, 14-16]. However, limited literature on nitride/alloy coating systems were published. The integration of $\mathrm{CrN}$ and Ni-alloy in a nanolayered feature was thus of great interest. Moreover, the control of the nanolayered configuration, layer microstructure, and related properties was not fully understood. In this study, Ni-P/CrN and Ni$\mathrm{Al} / \mathrm{CrN}$ nanolayered coatings were fabricated by dual-gun sputtering technique. The microstructure and phases of the multilayer coatings were controlled by process temperature during sputtering. The corrosion behavior of the multilayer coatings was investigated through electrochemical potentiodynamic analysis. The relationship between microstructure, phases, and corrosion behavior of the nanolayered Ni-P/CrN and $\mathrm{Ni}-\mathrm{Al} / \mathrm{CrN}$ coatings was discussed.

\section{Experimental Details}

The Ni-alloy/CrN nanolayered coatings were deposited on the silicon (100) and 420 stainless substrates by dual-gun sputtering technique. The $\mathrm{Ni}_{70} \mathrm{Al}_{30}$ and $\mathrm{Ni}_{75} \mathrm{P}_{25}$ (in at.\%) sputtering targets of $50.8 \mathrm{~mm}$ in diameter were employed for alloy layer fabrication. The $\mathrm{CrN}$ coating was deposited 
using a Cr target with $99.9 \%$ in purity and $\mathrm{N}_{2}$ gas as reactive source. Before deposition, the chamber was evacuated down to $4.0 \times 10^{-4} \mathrm{~Pa}$. The high purity Ar flow was introduced to a working pressure of $2.7 \times 10^{-1} \mathrm{~Pa}$. Presputtering was performed for 10 minutes to clean the target surface followed by the fabrication process. The target powers were D.C. $100 \mathrm{~W}$ for Ni-alloy and R.F. $200 \mathrm{~W}$ for Cr. The working pressure was $2.7 \times 10^{-1} \mathrm{~Pa}$ for Ni-alloy fabrication, while a working pressure of $6.7 \times 10^{-1} \mathrm{~Pa}$ was adopted for $\mathrm{CrN}$ due to the coinlet of $\mathrm{N}_{2}$ gas. The process temperature was fixed at $350^{\circ} \mathrm{C}$ for all coating assemblies. Nanolayered Nialloy/CrN coatings were prepared with fixed bilayer period of $10 \mathrm{~nm}$. The deposition time of individual layer of multilayer $\mathrm{Ni}$-alloy/CrN coatings during sequential sputtering were modified from 30 to 120 seconds. The total thickness of the multilayer coating systems was controlled around $1.0 \mu \mathrm{m}$. The thickness ratio of $\mathrm{Ni}$-alloy and $\mathrm{CrN}$ was fixed at 1.0. An X-ray diffractometer (Shimadzu, XRD-6000, Japan) with continuous $\theta-2 \theta$ scan was used to identify the phases in the coatings. The $2 \theta$ scan ranged from $30^{\circ}$ to $65^{\circ}$ with a step width of $0.02^{\circ}$ at a scanning speed of $6^{\circ} / \mathrm{min}$. The microstructure and surface morphology of the coatings were evaluated by FE-SEM (JSM-6500, JEOL, Japan). The compositions of selected areas of corroded coatings were inspected by an energy dispersion spectra inspected analyzer (INCA Energy 350, Oxford, UK). The depth profile was measured by Auger electron nanoscope (PHI 700, ULVACPHI, Japan). The corrosion behavior was measured by an electrochemical workstation (Jiehan-5000, Jiehan, Taiwan). The corrosion test was operated in $3.5 \mathrm{M} \mathrm{NaCl}$ aqueous solution at room temperature with the saturated calomel electrode (SCE) as the reference electrode. The scanning range was from -0.25 to $+0.25 \mathrm{~V}$ according to the open circuit potential of each sample. The potentiodyanmic curves were fitted using CorrView software. For convenience, coatings deposited on Si substrates were applied in crosssectional SEM observation, nano-Auger analysis, and XRD phase identification. Corrosion test and related analyses were conducted on coatings deposited on stainless steel substrates.

\section{Results and Discussion}

The cross-sectional view of the $\mathrm{Ni}-\mathrm{P} / \mathrm{CrN}$ and $\mathrm{Ni}-\mathrm{Al} / \mathrm{CrN}$ nanolayered coatings was presented in Figure 1. Smooth and dense coating configurations were recognized by sputtering fabrication process. The total thickness of all coatings estimated from FE-SEM images were about $1 \mu \mathrm{m}$. In the magnified regions, as indicated in Figure 1, the smooth configuration of the Ni-P and $\mathrm{CrN}$ stacking was observed. A bilayer thickness of approximately $10 \mathrm{~nm}$ could be measured. To confirm the multilayer feature, the depth analysis of $\mathrm{Ni}$ $\mathrm{P} / \mathrm{CrN}$ nanolayered coating was conducted by nano-Auger technique. The sputter time was set to be $3 \mathrm{~nm} / \mathrm{min}$. The depth profile of $\mathrm{Ni}, \mathrm{P}, \mathrm{Cr}$, and $\mathrm{N}$ showed a sequentially alternating distribution with a bilayer thickness around $10 \mathrm{~nm}$, as shown in Figure 2. A nanolayered structure of the coating was again demonstrated. The X-ray patterns of single and nanolayer coatings were shown in Figure 3. The diffraction peaks of $\mathrm{CrN}$ (111), (200), and (220) were found

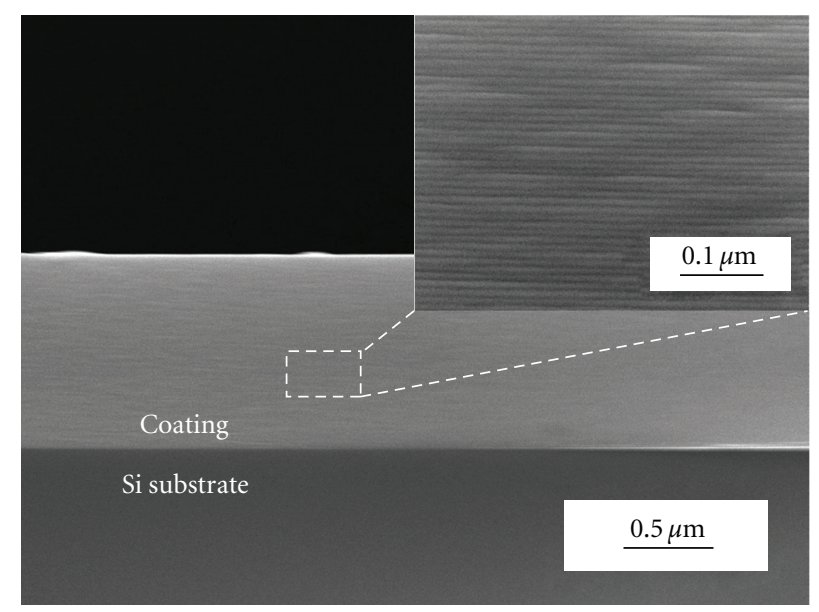

Figure 1: The cross-sectional FE-SEM images of NiP/CrN nanolayered coatings.

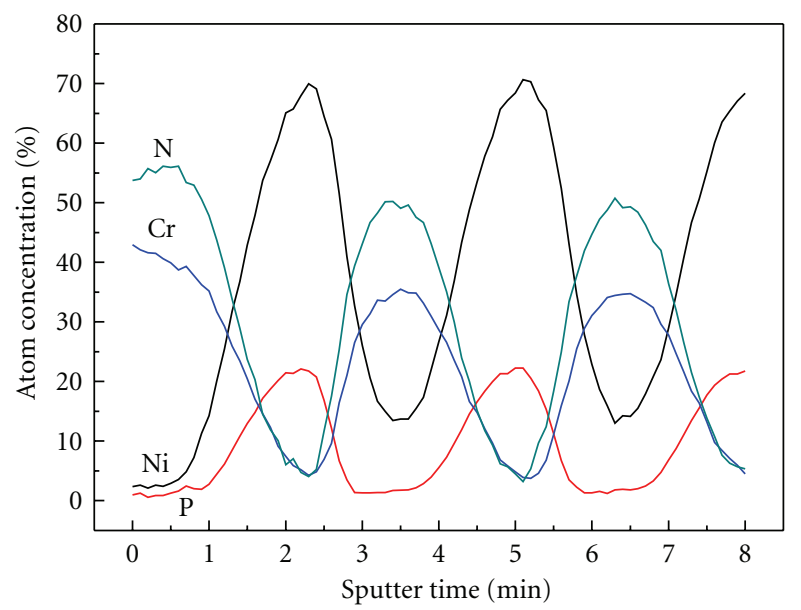

FIgure 2: Nano-Auger depth analysis of $\mathrm{NiP} / \mathrm{CrN}$ nanolayered coating.

for $\mathrm{CrN}$ coating. The $\mathrm{Ni}_{3} \mathrm{Al}$ precipitation was identified in the single-layer $\mathrm{Ni}-\mathrm{Al}$ coating, while the $\mathrm{Ni}$ crystalline phase and $\mathrm{Ni}_{3} \mathrm{P}$ precipitation was discovered in the $\mathrm{Ni}-\mathrm{P}$ coating. This indicated that sputtering process and substrate heating enhanced the precipitation of the Ni-P and Ni$\mathrm{Al}$ coatings. It should be noted that the peaks of $\mathrm{Ni}-\mathrm{P}$ and $\mathrm{Ni}-\mathrm{Al}$ intermetallic compounds were not fully resolved according to their broadened peak widths. In the $\mathrm{Ni}-\mathrm{Al} / \mathrm{CrN}$ and $\mathrm{Ni}-\mathrm{P} / \mathrm{CrN}$ coatings, the diffraction peaks were further broadened that a nanocrystalline/amorphous microstructure was expected. Since the thickness of each layer was $5 \mathrm{~nm}$, the precipitation of $\mathrm{Ni}-\mathrm{Al}, \mathrm{Ni}-\mathrm{P}$ intermetallics, and $\mathrm{CrN}$ phases was restricted by nanolayer feature. In the $\mathrm{Ni}-\mathrm{Al} / \mathrm{CrN}$ coating, three major peaks of $\mathrm{CrN}$ were recognized. However, a few peaks of $\mathrm{Ni}$ crystallites found in single $\mathrm{Ni}-\mathrm{Al}$ coating layer vanished. Similar situation was found for single Ni-P and nanolayered $\mathrm{Ni}-\mathrm{P} / \mathrm{CrN}$ coatings. It was believed that the precipitation of intermetallic compounds was suppressed by 


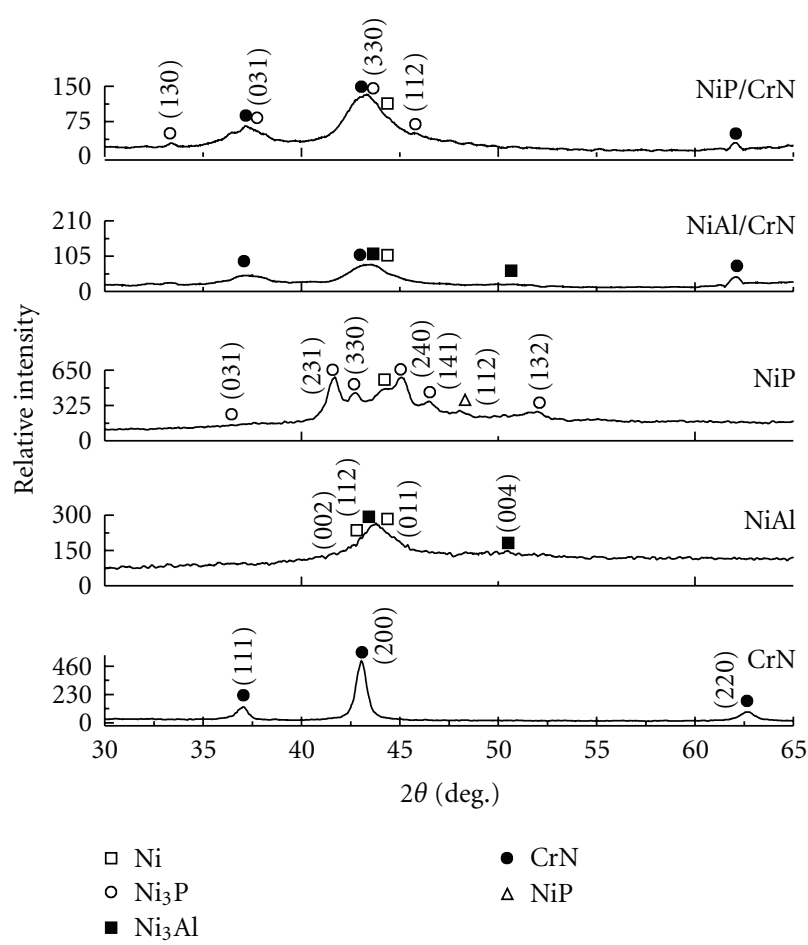

FIGURE 3: The XRD patterns of various coating systems.

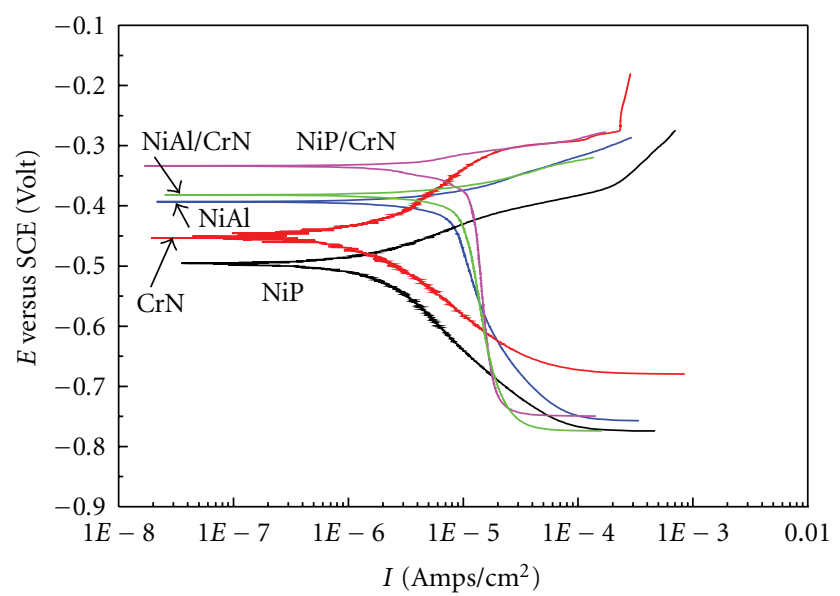

FIGURE 4: The electrochemical polarization curves of various coating systems.

nanolayered sequential deposition. To summarize, the Ni$\mathrm{Al}$ and Ni-P single coatings exhibited precipitated structure, while nanolayered coatings showed $\mathrm{CrN}$ phases with $\mathrm{Ni}$-alloy nanocrystalline layers.

The results of potentiodynamic analysis for various coating systems were indicated in Figure 4 . The trend of corrosion resistance in different coatings systems could be discovered. The numberical results of $I_{\text {corr }}$ and $E_{\text {corr }}$ were listed in Table 1. The $E_{\text {corr }}$ values were from -0.64 to $-0.33 \mathrm{~V}$. The $I_{\text {corr }}$ values ranged from $1.42 \times 10^{-5}$ to $1.14 \times 10^{-6} \mathrm{~A} / \mathrm{cm}^{2}$. All the coatings showed better corrosion potentials than that of AISI 420 substrate. Firstly, for the
TABLE 1: The $E_{\text {corr }}$ and $I_{\text {corr }}$ values of various coating systems.

\begin{tabular}{lcc}
\hline Materials & $E_{\text {corr }}(\mathrm{V}$ versus SCE $)$ & $I_{\text {corr }}\left(\mathrm{A} / \mathrm{cm}^{2}\right)$ \\
\hline $420 \mathrm{SS}$ & -0.64 & $1.42 \times 10^{-5}$ \\
$\mathrm{NiAl}$ & -0.39 & $1.20 \times 10^{-5}$ \\
$\mathrm{NiP}$ & -0.50 & $1.34 \times 10^{-6}$ \\
$\mathrm{CrN}$ & -0.45 & $1.14 \times 10^{-6}$ \\
$\mathrm{NiAl} / \mathrm{CrN}$ & -0.38 & $1.18 \times 10^{-5}$ \\
$\mathrm{NiP} / \mathrm{CrN}$ & -0.33 & $7.50 \times 10^{-6}$ \\
\hline * The test was conducted in a $3.5 \mathrm{M} \mathrm{NaCl}$ solution at room temperature.
\end{tabular}

single-layer coatings, the $\mathrm{Ni}-\mathrm{Al}$ coating showed the most nonnegative $E_{\text {corr }}$ value of -0.39 Volts. The Ni-P and $\mathrm{Cr}-\mathrm{N}$ coatings exhibited the less $I_{\text {corr }}$ values of $1.14 \times 10^{-6}$ and 1.34 $\times 10^{-6}$, respectively. This could be due to different corrosion behavior for the Ni-Al, Ni-P, and $\mathrm{CrN}$ coatings. For the Ni-Al coating, the corrosion occurred homogeneously and isotropically on coating surface [10]. On the other hand, the Ni$\mathrm{P}$ and $\mathrm{CrN}$ showed in-depth pitting corrosion on localized areas $[12,17]$. This could be referred to the corroded surface morphology of Ni-Al, Ni-P, and $\mathrm{CrN}$, as shown in Figures 5(a), 5(b), and 5(c). Large but homogeneously distributed corroded areas were observed for the Ni-Al coating. On the contrary, localized small etching pits were found for $\mathrm{Ni}-\mathrm{P}$ and CrN coatings, as indicated in Figures 5(b) and 5(c). Secondly, take $\mathrm{Ni}-\mathrm{Al}, \mathrm{CrN}$, and $\mathrm{Ni}-\mathrm{Al} / \mathrm{CrN}$ coatings for comparison, the $E_{\text {corr }}$ and $I_{\text {corr }}$ values of these two coatings were similar. Figure 5(d) showed the surface morphology of $\mathrm{Ni}-\mathrm{Al} / \mathrm{CrN}$ coating. The pits were less than other single-layer coatings. However, the large $I_{\text {corr }}$ of $\mathrm{Ni}$-Al was not significantly decreased by nanolayered feature. Through EDX analysis, a few $\mathrm{Fe}$ concentration were detected in the single $\mathrm{Ni}-\mathrm{Al}$ coating, indicating some of the $\mathrm{Ni}-\mathrm{Al}$ was coating etched away. Nevertheless, in the $\mathrm{Ni}-\mathrm{Al} / \mathrm{CrN}$ coating, the substrate was well protected by the coating. The corrosion behavior of $\mathrm{Ni}-\mathrm{P}, \mathrm{CrN}$, and $\mathrm{Ni}-\mathrm{P} / \mathrm{CrN}$ was also compared. The Ni$\mathrm{P} / \mathrm{CrN}$ exhibited a superior corrosion resistance than those of other thin films. It should be noted that the Ni-P coating exhibited a lowest $E_{\text {corr }}$ value between all materials systems. The enhancement of nanolayered $\mathrm{Ni}-\mathrm{P} / \mathrm{CrN}$ as compared to $\mathrm{CrN}$ coating was evident. The surface morphology of $\mathrm{Ni}-\mathrm{P} / \mathrm{CrN}$ after corrosion test was shown in Figure 5(e). The etching pits were significantly reduced. The corrosion resistance was thus improved effectively for the combination of $\mathrm{Ni}-\mathrm{P}$ and $\mathrm{CrN}$ coatings.

The corrosion behaviors of the nanolayered Ni-P/CrN and $\mathrm{Ni}-\mathrm{Al} / \mathrm{CrN}$ coatings were taken into comparison. Even the $E_{\text {corr }}$ of $\mathrm{Ni}-\mathrm{P}$ was lower than that of $\mathrm{Ni}-\mathrm{Al}$ coating, as the Ni-P and Ni-Al were deposited with $\mathrm{CrN}$ to form nanolayered coatings, the corrosion resistance of $\mathrm{Ni}-\mathrm{P} / \mathrm{CrN}$ was better than that of $\mathrm{Ni}-\mathrm{Al} / \mathrm{CrN}$ nanolayered coating. This was because Ni-Al layer exhibited a severer layer area corrosion mechanism, while similar localized pitting corrosion was found for both Ni-P and CrN layers. Nevertheless, nanolayered coatings exhibited good protection from corrosion attacks. The corroded surface morphologies of two nanolayered coatings were shown in Figure 6. Though 


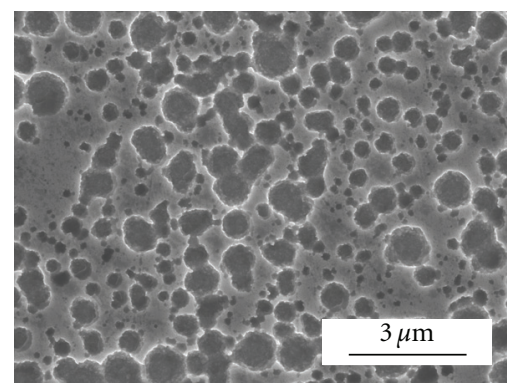

(a)

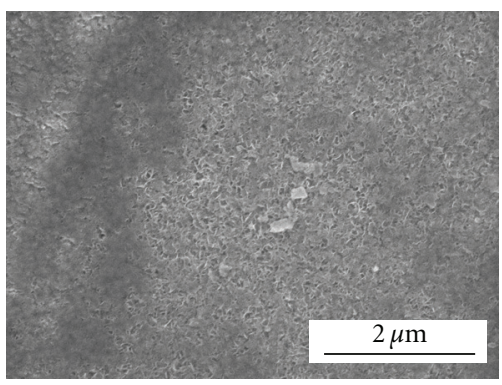

(c)

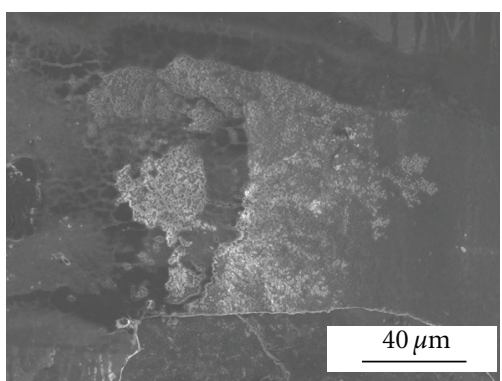

(b)

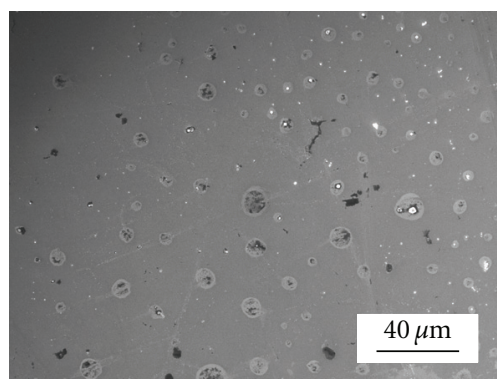

(d)

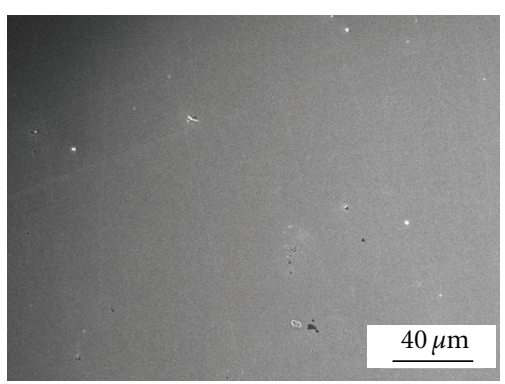

(e)

Figure 5: The SEM surface images of (a) NiAl, (b) NiP, (c) CrN, (d) NiAl/CrN nanolayered, and (e) NiP/CrN nanolayered coatings on stainless steel substrates after corrosion test.

etching pits were observed at localized area, the substrate was still well covered with coating. This phenomenon was consistent to the fitted results of potentiodynamic curves. Corrosion resistance was improved through $\mathrm{Ni}-\mathrm{P} / \mathrm{CrN}$ and $\mathrm{Ni}-\mathrm{Al} / \mathrm{CrN}$ nanolayered feature.

The corrosion mechanisms of the nanolayered coatings were shown in Figure 7. First, the corrosion resistance of $\mathrm{Ni}-\mathrm{Al} / \mathrm{CrN}$ nanolayered could be slightly improved by the nanolayer feature. Localized etching pits in $\mathrm{CrN}$ layers with homogenous corrosion behavior in the $\mathrm{Ni}$ - $\mathrm{Al}$ layer were expected for the $\mathrm{Ni}-\mathrm{Al} / \mathrm{CrN}$ coatings. In the $\mathrm{Ni}$ $\mathrm{P} / \mathrm{CrN}$ nanolayered coating, due to the pitting behavior of both Ni-P and CrN layers, the corrosion attach detoured in the interface and elongated the corrosion path. The corrosion resistance was thus improved by such configuration. To sum up, the combination of Ni-alloy and $\mathrm{CrN}$ to form a nanolayered coating was beneficial to corrosion protection in surface coatings. The introduction of interphase interface elongated the corrosion path and retarded the corrosion attack in the $\mathrm{Ni}$-alloy/CrN nanolayered coatings.

\section{Conclusions}

Nanolayered $\mathrm{Ni}$-alloy/CrN coatings systems were successfully fabricated by dual-gun sputtering technique. The coatings showed smooth and dense structure, as revealed in FE-SEM cross-sectional images. The $\mathrm{Ni}-\mathrm{P} / \mathrm{CrN}$ and $\mathrm{Ni}-$ $\mathrm{Al} / \mathrm{CrN}$ nanolayered layer coatings exhibited a nanocrystalline/amorphous microstructure because of the restricted precipitation by nanolayer feature. For the single-layer coatings, $\mathrm{Ni}$-Al exhibited a homogeneously large area corrosion phenomenon, while localized pitting within limited regions was found for $\mathrm{NiP}$ and $\mathrm{CrN}$ coatings. Through Tafel analysis, the Ni-alloy/CrN nanolayered coating exhibited a superior corrosion resistance than monolayer coatings. Moreover, the $\mathrm{Ni}-\mathrm{P} / \mathrm{CrN}$ coating showed an even greater corrosion resistance due to its localized pitting corrosion behavior for both $\mathrm{Ni}-\mathrm{P}$ and $\mathrm{CrN}$ layers. Through morphology observation, the nanolayered $\mathrm{Ni}-\mathrm{Al} / \mathrm{CrN}$ and $\mathrm{Ni}-\mathrm{P} / \mathrm{CrN}$ coatings maintained a solid integrity after corrosion test. The combination of $\mathrm{Ni}$ $\mathrm{P}$ and $\mathrm{CrN}$ in a nanolayered coating structure to promote the corrosion resistance was demonstrated. 


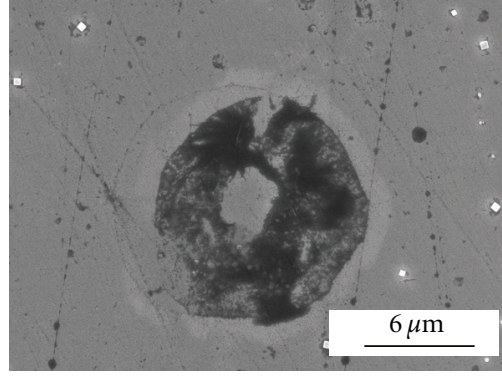

(a)

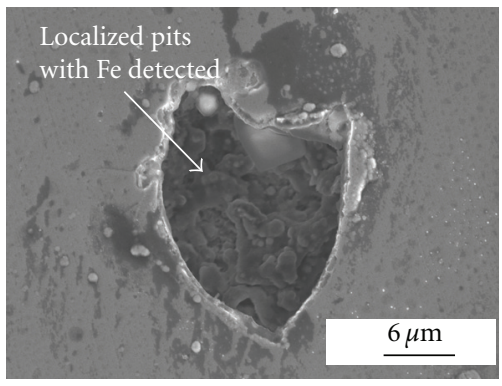

(b)

FIgURE 6: The SEM surface images of corroded regions of (a) NiP/CrN, (b) NiAl/CrN nanolayered coatings on stainless steel substrates.

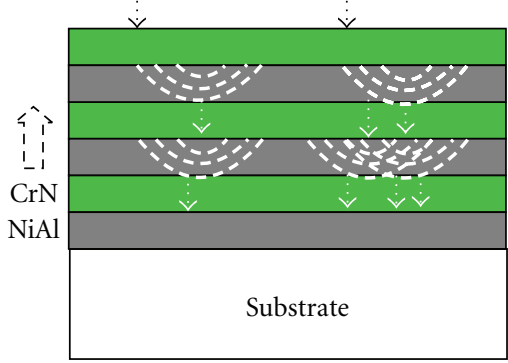

(a)

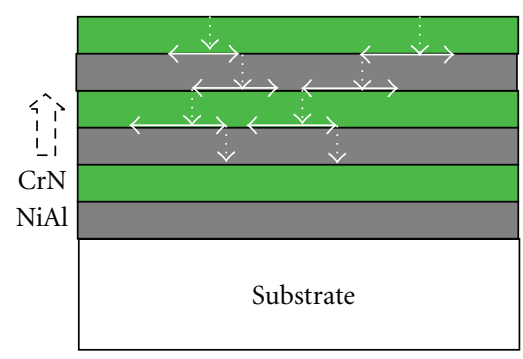

(b)

FIGURE 7: The schematic diagram of corrosion mechanism with (a) $\mathrm{NiAl} / \mathrm{CrN}$ and (b) NiP/CrN nanolayered coatings.

\section{Acknowledgment}

This work is supported by the National Science Council, Taiwan, under Contracts nos. NSC-97-2221-E-239-008 and NSC 98-2221-E- 239-009-MY3.

\section{References}

[1] S.-K. Tien, J.-G. Duh, and J.-W. Lee, "Oxidation behavior of sputtered CrN/AlN multilayer coatings during heat treatment," Surface and Coatings Technology, vol. 201, no. 9-11, pp. 5138-5142, 2007.

[2] Y.-Z. Tsai and J.-G. Duh, "Thermal stability and microstructure characterization of $\mathrm{CrN} / \mathrm{WN}$ multilayer coatings fabricated by ion-beam assisted deposition," Surface and Coatings Technology, vol. 200, no. 5-6, pp. 1683-1689, 2005.

[3] P. C. Yashar and W. D. Sproul, "Nanometer scale multilayered hard coatings," Vacuum, vol. 55, no. 3, pp. 179-190, 1999.

[4] M.-S. Wong, G.-Y. Hsiao, and S.-Y. Yang, "Preparation and characterization of $\mathrm{AlN} / \mathrm{ZrN}$ and AlN/TiN nanolaminate coatings," Surface and Coatings Technology, vol. 133-134, pp. $160-165,2000$.

[5] D. C. Cameron, R. Aimo, Z. H. Wang, and K. A. Pischow, "Structural variations in CrN/NbN superlattices," Surface and Coatings Technology, vol. 142-144, pp. 567-572, 2001.

[6] I. Milošev, H.-H. Strehblow, and B. Navinšek, "XPS in the study of high-temperature oxidation of $\mathrm{CrN}$ and TiN hard coatings," Surface and Coatings Technology, vol. 74-75, no. 2, pp. 897-902, 1995.

[7] J.-N. Tu, J.-G. Duh, and S.-Y. Tsai, "Morphology, mechanical properties, and oxidation behavior of reactively sputtered CrN films," Surface and Coatings Technology, vol. 133-134, pp. 181-185, 2000.

[8] A. Kawashima, H. Habazaki, and K. Hashimoto, "Highly corrosion-resistant Ni-based bulk amorphous alloys," Materials Science and Engineering A, vol. 304-306, no. 1-2, pp. 753$757,2001$.

[9] G. Lu and G. Zangari, "Corrosion resistance of ternary NiP based alloys in sulfuric acid solutions," Electrochimica Acta, vol. 47, no. 18, pp. 2969-2979, 2002.

[10] J. G. González-Rodriguez, J. C. Colín, S. Serna, B. Campillo, and J. L. Albarran, "Effect of macroalloying with $\mathrm{Cu}$ on the corrosion resistance of rapidly solidified $\mathrm{NiAl}$ intermetallic in $0.5 \mathrm{M} \mathrm{H}_{2} \mathrm{SO}_{4}$," Materials Science and Engineering A, vol. 448, no. 1-2, pp. 158-164, 2007.

[11] F.-B. Wu, J.-J. Li, and J.-G. Duh, "Evaluation of the mechanical properties and tribological behavior of the $\mathrm{CrN}$ coating deposited on mild steel modified with electroless Ni interlayer," Thin Solid Films, vol. 377-378, pp. 354-359, 2000.

[12] J.-S. Chen, J.-G. Duh, and F.-B. Wu, "Microhardness and corrosion behavior in CrN/electroless Ni/mild steel complex coating," Surface and Coatings Technology, vol. 150, no. 2-3, pp. 239-245, 2002.

[13] F.-B. Wu and J.-G. Duh, "Scratch behavior and in situ acoustic emission analysis of PVD chromium nitride coatings on mild steel with electroless nickel interlayers," Surface and Coatings Technology, vol. 162, no. 1, pp. 106-112, 2003.

[14] Q. Yang and L. R. Zhao, "Thermal stability of polycrystalline TiN/CrN superlattice coatings," Journal of Vacuum Science and Technology A, vol. 21, no. 3, pp. 558-562, 2003.

[15] A. Bukaluk, "Auger electron spectroscopy investigations of the effect of degradation of depth resolution and its influence on the interdiffusion data in thin film $\mathrm{Au} / \mathrm{Ag}, \mathrm{Cu} / \mathrm{Ag}, \mathrm{Pd} / \mathrm{Au}$ and Pd/Cu multilayer structures," Applied Surface Science, vol. 175176, pp. 790-796, 2001.

[16] A. Bukaluk, "Influence of depth resolution on the interdiffusion data in thin film bilayer and multilayer Ag/Pd structures," Vacuum, vol. 63, no. 1-2, pp. 119-126, 2001. 
[17] M. Ürgen and A. F. Çakir, "The effect of heating on corrosion behavior of TiN- and CrN-coated steels," Surface and Coatings Technology, vol. 96, no. 2-3, pp. 236-244, 1997. 



The Scientific World Journal

Submit your manuscripts at

http://www.hindawi.com

\section{World Journal}

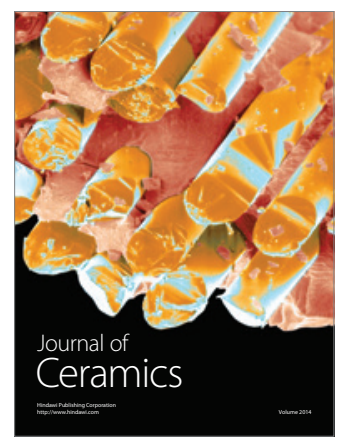

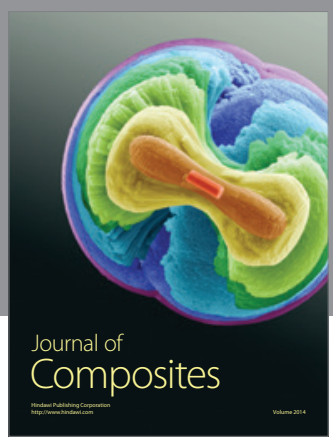
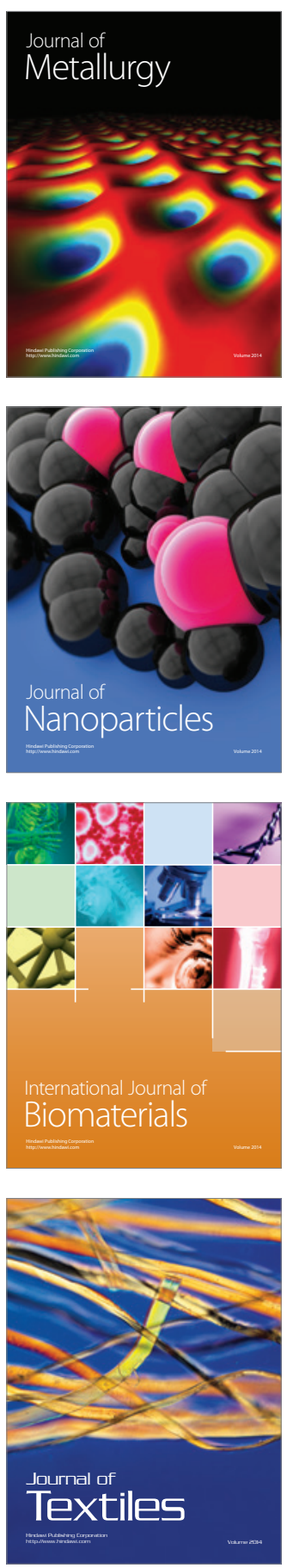